\title{
Diagnostics of gas turbines based on changes in thermodynamics parameters
}

\author{
Marián Hocko ${ }^{1, a}$, Marek Klimko² \\ ${ }^{1}$ Technical University in Košice, Department of Aviation Engineering, Rampová 7, 04121 Košice, Slovak Republic \\ ${ }^{2}$ University of West Bohemia, Department of Power System Engineering, Univerzitni 8, 30614 Pilsen, Czech Republic
}

\begin{abstract}
This article is focused on solving the problems of determining the true state of gas turbine based on measured changes in thermodynamic parameters. Dependence between the real individual parts for gas turbines and changing the thermodynamic parameters were experimentally verified and confirmed on a small jet engine MPM-20 in the laboratory of the Department of Aviation Engineering at Technical University in Košice. The results of experiments confirm that the wear and tear of basic parts for gas turbines (turbo-compressor engines) to effect the change of thermodynamic parameters of the engine.
\end{abstract}

\section{Introduction}

Diagnostics of gas turbines (GT) based on changes in thermodynamics parameters is one of the most spread and efficient methods of their evaluation. This method is used to analyze mainly the capacity of GT to ensure their basic function - to supply required power.

Various types of malfunction and deterioration of the flow components are typical for different types of GT in the stage of their testing and operation.

Operational factors, among which are acceleration, deceleration, heat non-stationarity of construction components, friction parts wear, change in climatic conditions, sucking of foreign objects etc., influence GT during the operation. The influence of operational factors manifests in extension of radial clearance in blading machines, wear of interacting components, quality of sealing, erosive changes in a blade profile shape, appearance of clearance in the blade control system of compressor rectifier, clogging of an engine flow part and cooling system channels.

Wear of gas generator components is the basic cause of thermodynamic parameters impairment. Typical failures of the engine flow part are gas turbine failures cracks on individual rectifying and rotor blades, erosive wear of stationary blades edges. Among other failures there are damage in compressor blades due to the sucking of foreign objects and erosive wear, fuel nozzles burnout, flue of combustion chambers, air leaks through flange joints of the compressor and combustion chamber at the points of fixing pipes, valves, pipe plugs and flanges of a gas turbine.

\section{Requirements on checked parameters}

An ideal case shall require measuring gas flow parameters (total pressure and total temperature) in all characteristic cross sections: at the inlet to the compressor $\mathrm{P}_{1 \mathrm{C}}, \mathrm{T}_{1 \mathrm{c}}$, combustion chamber $\mathrm{p}_{2 \mathrm{c}}, \mathrm{T}_{2 \mathrm{c}}$ and gas chamber $p_{3 c}, T_{3 c}$ for a perfect diagnosis of the GT flow part. The list of measured parameters is substantially lower in real life, although there is a trend to increase it. Total pressure $\mathrm{p}_{0 \mathrm{c}}$ and total air temperature $\mathrm{T}_{0 \mathrm{c}}$ at the engine inlet, and total pressure $p_{2 c}$, total air temperature $T_{2 c}$ behind the compressor, and total pressure $\mathrm{p}_{4 \mathrm{c}}$ and total gas temperature $T_{4 c}$ behind the gas turbine, are the most frequently measured parameters of current engines. The essential measured parameters are engine rotor speed and those parameters, which characterize a change in controlled parameters of engine mechanization, such as a value of extracted air needed for a defroster and other systems. Most of listed parameters participate in an engine regulating process (engine regulating principle), which is a condition for their use. Total gas temperature behind a low-pressure gas turbine (LPT) $\mathrm{p}_{4 \mathrm{c}}$ represents a complex parameter, as for sensitivity, characterizing a condition of the engine flow component. Increase in sensitivity may be induced by various causes - a growth of air leaks from a high-pressure compressor (HPC) $\mathrm{p}_{2 \mathrm{c}}$, impairment of efficiency (characteristics) of a compressor and a gas turbine. Air temperature around a combustion turbine enables to detect hot air leaks from HPC. A character of a temperature change behind HPC $\mathrm{p}_{2 \mathrm{c}}$ confirms the change of HPC efficiency, depending on the number of duty hours.

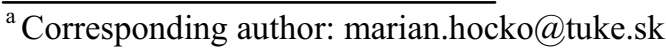




\section{Algorithms of diagnosing the engine flow section}

Currently, the processes running in GT (turbocompressor engines), are sufficiently well controlled. Generally, they can be described by a system of nonlinear equations, which are interrelated by status parameters (coefficients of total pressure preservation, efficiency of individual nodes, flow sections areas, values of gas and air leaks) and measured parameters (total pressures and total air and gas temperatures in various engine cross-sections, rotor speed, fuel consumption, power etc.).

An origin of failures (fluent or step ones) is usually subject to a change of efficiency (characteristics) of nodes, which cannot be measured, yet this change demonstrates immediately in a shift of an engine thermodynamic and gas dynamic parameters. An interaction between measured parameters and properties of nodes is described by thermodynamic and gas dynamic mathematical models on various complexity levels. The given models are utilized in all methods of malfunction detection.

Methods of detecting a flow section malfunction of GT (turbo-compressor engines) may be divided into two basic types:

- Detecting malfunction based on the analysis of measured parameters;

- Detecting malfunction on the basis of identifying a thermo-gas dynamic model, followed by malfunction detection based on the analysis of nodes properties parameters.

A selection of the model form, which will be the most suitable for realization in practice, shall depend on the ongoing life cycle of GT (turbo-compressor engines). Advantages of the first mentioned method prevail, depending on the operating time length and collected empirical information on the engine condition. These methods additionally provide a good illustration when implementing an expert analysis on the group of objects, diagnostics, and regression analysis of time series. When using the methods of the first type, parameter values are recalculated on standard atmospheric conditions and computational mode.

So called unrestrained parameters of nodes characteristics are utilized the most for the methods of the second type. Using a mathematical model (where a model identification is used), parameter values for various failures are calculated and a deviation from common parameter values is determined, for given external conditions and the engine operational mode. Obtained differences represent "separateness" of parameters. The minimum "separateness" of parameters is reached for such a state, which corresponds with the most probable malfunction defined in the model. The model is based on the model identification and a compilation of possible malfunctions with a small repeatability. A decision of a concrete turbo-compressor engines condition is carried out on the basis of the minimum "separateness" principle. Despite the positive properties of this method, there are flaws as well, which include a low illustration when performing an expert analysis on the group of diagnostics objects and, most of all, when analyzing time series.

Admissible values in characteristics changes of diagnosed nodes are defined on the basis of statistics data acquired during testing and operation of those engines, which showed malfunctions, and those, which worked off their technical life failure-free.

Random effects influence the computational results in the process of parameter analysis in operational conditions:

- Changes in air extractions or the performance, demanded by the engine or other devices,

- Inaccuracies of measurements and parameter registration,

- Inaccuracies in keeping the engine operation by a regulation system,

- Air flow non-uniformity at the engine inlet,

- Change in a generating set load,

- Technological scattering of geometrical dimensions, nodes characteristics during engine production,

- Wear of engine parts in the operational process,

- Humidity, air turbulence, wind direction and velocity.

Algorithms of mathematical models identification are traditionally used to diagnose the flow part failures, and "trend-analysis" algorithms are used to detect a time change tendency of measured parameters in GT (turbocompressor engines) automatized diagnostics systems. A mathematical model identification consists of the determination of differences between measured and computed parameter values. The use of "trend-analysis" procedure enables, based on the deviation between measured and computed parameter values, to define tendencies of their change, depending on the operational time on the basis of indeterminate errors of measurements. It is difficult to guarantee the diagnostics of a flow part condition at changeable operation modes of the engine at a relatively low frequency of information registration by panel registration systems. The most suitable mode to diagnose the GT (turbo-compressor engines) part is the engine computational mode. General requirements for a selection of diagnostics modes are possible to define as follows:

- The engine operational mode must be high enough to differ changes in parameters, which were induced by the change of the flow part state from changes induced by random factors;

- Measuring parameters must be subject to the least amount of random non-measured effects due to the mode selection with the maximum volume of identical (similar) external conditions and parameters of the engine operational mode.

The engine has maximum parameter values at the maximum operational duty, which leads to the drop in measurement inaccuracies (faults). However, some problems appear, which are related to ensuring similar conditions of ongoing processes of massive rotor components overheating, valve closedowns etc.

Forming the optimum time and the selection size to determine the parameter values are chosen on the basis of the registered engine information oddness, as well as the length of ongoing processes in the engine. 
A concept of a "reference point" is used fairly frequently in practical life. This concept enables to define a set up mode, as well as parameter mean values computed from selected values. It is necessary to recalculate the parameters onto the international standard atmospheric conditions (ISA) to eliminate the influence of meteorological conditions on the checked parameters values of GT (turbo-compressor engines). It is convenient to perform this recalculation on the standard atmospheric conditions, which correspond to the selected reference points, to decrease the inaccuracy influence during recalculating.

The ISA recalculation is performed using standard gas dynamic functions, which conform to the reference point of the given ISA type.

The values of acquired recalculated parameters on ISA, regarding the reference point of the given type, are related to close, though usually different, engine operational modes. Therefore, it is necessary to carry out their recalculation on the computational mode, to make the parameters value real. To be able to realize such a process, it is needed:

- To obtain the functional dependence course, which sufficiently describes a change in the parameter depending on the mode parameter,

- To define how the behaviour of this dependence changes for various engines,

- To determine the relation between a real dependence and dependence acquired via the engine mathematical model,

- To define the character of a functional dependence change for increased number of the engine operational hours (the shift of the characteristics, or its deviation),

- To define the character of the influence of extracted air flow rate, the position of compressor mechanization components etc.

The use of the method of parameter values recalculation towards standard atmospheric conditions, and consequently onto the computational mode, provides a possibility to create dependencies of parameter changes against the engine operational time. A graphic illustration of those dependencies is a useful tool to define a perfect visual formulation of parameter changes and long-term tendencies.

Possibilities of the flow part diagnostics by the time series method are open, with regard to the above mentioned. The easiest method is to determine basic parameter values at the beginning of the engine operation, and to consequently check up the deviation of recalculated parameters towards basic parameters.

\section{Experimental verification of the influence of changes in the inlet device of the jet turbo-compressor engine on thermodynamic parameters}

The experiment has focused on monitoring changes in thermodynamic parameters MPM-20 when the flow conditions in its inlet device have changed.

The theory of small changes, described for sub-critical flow conditions in an outlet nozzle for MPM-20, defines that a change in conditions in an inlet device will manifest itself as a change in all parameters of an operational process of a single-flow turbo-compressor engines. Four sets of experimental measurements have been prepared to verify this theory in practice; and their objective has been to stepwise throttle the air flow through the inlet device MPM-20. The measured values of parameters are compared with values acquired during a calibration measurement and theoretical calculation on the basis of the small changes theory. Four experimental measurements have been realized in stages as follows:

1. Air flow through the inlet device MPM-20 without an inlet sieve.

2. Air flow through the inlet device MPM-20 with a sieve of the aperture dimension of 1,5 x 1,5 mm.

3. Air flow through the inlet device MPM-20 with a doubled sieve (a sieve with the aperture dimension of 1,5 $\mathrm{x} 1,5 \mathrm{~mm}$ and a sieve with the aperture dimension of 2,5 x 2,5 mm).

4. Air flow through the inlet device MPM-20 with a fluorescent TV screen with holes of $0,4 \mathrm{~mm}$ in a diameter.

\subsection{Air flow through the inlet device without an inlet sieve}

An inlet sieve has been removed from the inlet device MPM-20 to follow the conditions of the given experiment.

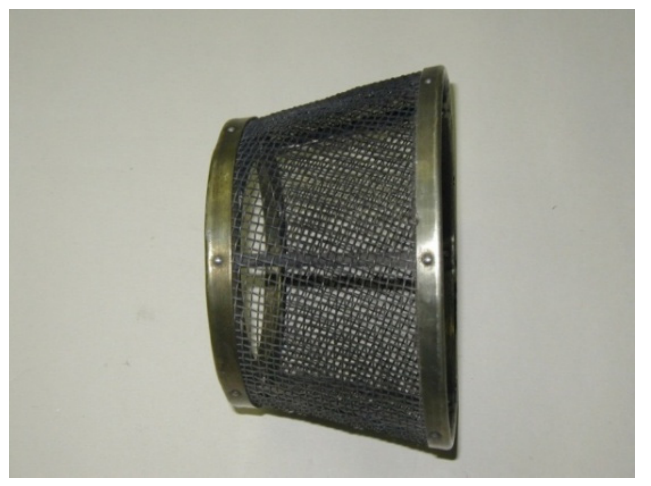

Figure 1. View to the inlet sieve MPM-20.

10 measurements have been carried out during the experiment, whereas the same parameters as for the calibration measurement have been measured and analysed. The operational mode of MPM-20 has been set up onto such values, that correspond to the computational mode.

Differences for individual parameters are minimum and they range within $-5,4 \%$ (static pressure behind the gas turbine $\mathrm{p}_{4 \mathrm{c}}$ ) up to $+2,9 \%$ (total gas temperature behind the gas turbine $\mathrm{T}_{4 \mathrm{c}}$ ), as implied from the data mentioned in Table 1, in which the measured values for parameters during experimental measurements without an inlet sieve and during the calibration measurement are compared. Most of observed parameters did not change much, even though the flow area at the inlet into MPM20 enlarged by $35 \%$ by removing the inlet sieve. 
The results obtained by direct measurements on MPM-20 without an inlet sieve confirm that a selection of a wire diameter as well as an aperture dimension have been optimized by the engine producer, so that the used sieve can provide a protection against the sucking of foreign objects at the minimum influence of MPM-20 parameters. A calculation of a force $F_{T}$ and specific fuel consumption $\mathrm{cm}$ has been made, based on measured parameters.

\subsection{Air flow through the inlet device without an inlet sieve}

A fine inlet sieve has been implemented during the second experimental measurement. The total area of the inlet sieve was $0,078593 \mathrm{~m}^{2}$. The wire area of the inlet sieve takes up $34,984 \%$ when using the wire sieve of 1,5 $\mathrm{x} 1,5 \mathrm{~mm}$ of the aperture dimension and $0,3 \mathrm{~mm}$ of the wire thickness.

The measured parameter values of MPM-20 listed in Tab. 1 are very near to the measured values of calibration measurements with the original sieve.

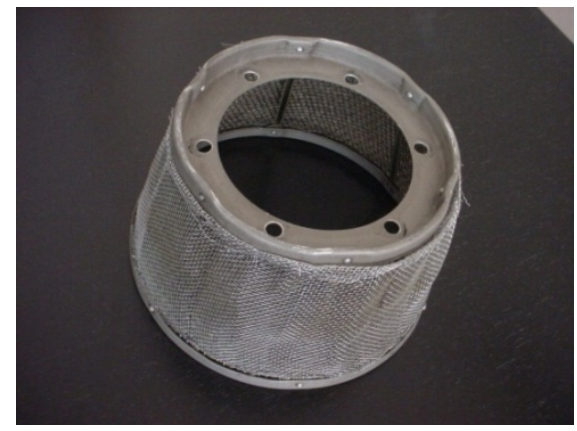

Figure 2. View to the fine inlet sieve of MPM-20.

\subsection{Air flow through the inlet device with a doubled inlet sieve}

During the third experimental measurement, a sieve with $1,5 \times 1,5 \mathrm{~mm}$ of an aperture dimension and a wire thickness of $0,3 \mathrm{~mm}$ was mounted on the original inlet device of MPM-20, which decreased the flow area down to $58 \%$. Based on this drop in the inlet device flow area, the measured parameters have changed, which led to the change in the dependent parameters. The biggest change has been observed in the stage of gas expansion on the gas turbine $\pi_{\mathrm{T}}$ (by 19,194\%) and in the change of the total gas temperature behind the gas turbine $\mathrm{T}_{4 \mathrm{c}}$ (by $4,475 \%$ ).

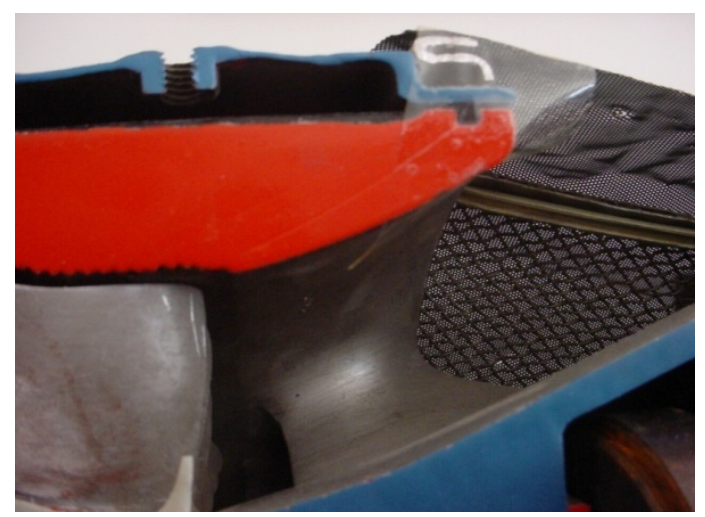

Figure 3. View to the inlet with the finest sieve from the inside.

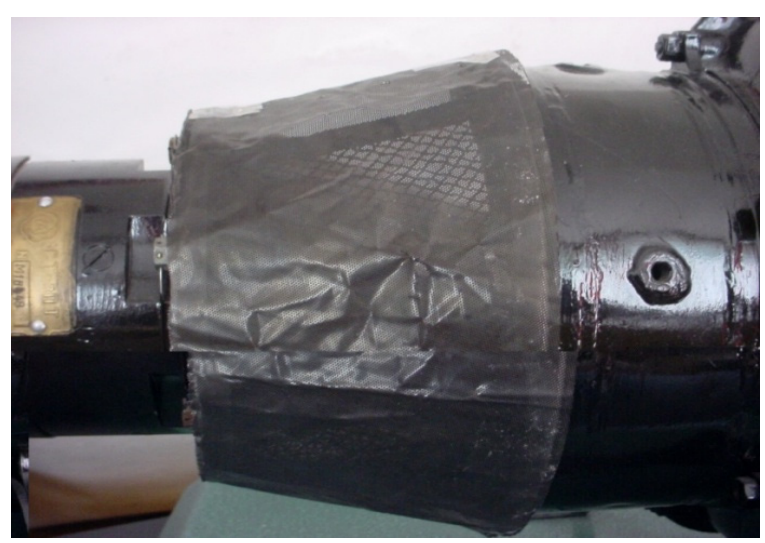

Figure 4. View to the inlet device with the finest sieve from the outside.

\subsection{Air flow through the inlet device with a doubled inlet sieve}

A sieve with circle holes of $0,4 \mathrm{~mm}$ was implemented during the fourth experimental measurement instead of the original MPM-20 sieve, which resulted in a decrease of the flow area of the inlet MPM-20 device by $83 \%$. A decrease in the flow area of the engine inlet device led to a significant degradation in measured parameters compared to calibration measured parameters $\left(\Delta \mathrm{p}_{2 \mathrm{C}}=-48\right.$ 978,8 Pa, $\Delta \mathrm{p}_{3}=24198,5 \mathrm{~Pa}, \Delta \mathrm{p}_{4}=-24957,82 \mathrm{~Pa}, \mathrm{~T}_{2 \mathrm{c}}=-$ $11,6 \mathrm{~K}, \Delta \mathrm{T}_{3 \mathrm{c}}=-92,4 \mathrm{~K}, \Delta \mathrm{T}_{4 \mathrm{c}}=-177,5, \mathrm{c}_{\mathrm{h}}==-4,3465$ kg.h ${ }^{-1}, \Delta \pi_{\mathrm{T}}=0,6, \Delta \pi_{\mathrm{Kc}}=-0,509$ a $\Delta \pi_{\mathrm{VD}}=-0,257$. 
Table 1. Change in MPM-20 parameters when throttling the inlet system.

\begin{tabular}{|c|c|c|c|c|c|c|}
\hline PARAMETER & $\mathbf{S}_{\text {vst. }}$ & $\mathbf{p}_{\mathbf{H}}$ & $\mathbf{T}_{\mathbf{H}}$ & Time of operation & $\mathbf{p}_{2, \mathrm{~K}}{ }^{\prime}$ & $\mathbf{p}_{2 \mathrm{c}, \mathrm{K}}{ }^{\prime}$ \\
\hline UNIT & $\%$ & $\mathbf{P a}$ & $\mathbf{K}$ & second & $\mathbf{P a}$ & $\mathbf{P a}$ \\
\hline Inlet system without a sieve & 100 & 100525,3 & 288,75 & 51,0 & 178967,1 & 388941,8 \\
\hline Inlet system with a fine sieve & 80 & 100365,6 & 290,95 & 49,7 & 179136,7 & 390028,1 \\
\hline Inlet system with a basic sieve & 65 & 99885,82 & 290,65 & 51,7 & 180787,9 & 391185,7 \\
\hline Inlet system with a doubled sieve & 58 & 100125,3 & 290,65 & 49,7 & 198319,4 & 397633,7 \\
\hline Inlet system with the finest sieve & 17 & 99991,98 & 290,29 & 50,0 & 213852,3 & 428407,3 \\
\hline PARAMETER & $\mathbf{p}_{2 c}$ & $\mathbf{p}_{3}$ & $\mathbf{p}_{4}$ & $\mathbf{T}_{2 \mathrm{c}}^{\prime}$ & $\mathbf{T}_{2 \mathrm{c}}$ & $\mathbf{T}_{3 c}$ \\
\hline UNIT & $\mathbf{P a}$ & $\mathbf{P a}$ & $\mathbf{P a}$ & $\mathbf{K}$ & $\mathbf{K}$ & $\mathbf{K}$ \\
\hline Inlet system without a sieve & 351178,4 & 351524,7 & 128716,48 & 458,35 & 459,55 & 1169,25 \\
\hline Inlet system with a fine sieve & 351571,5 & 351462,6 & 128977,1 & 458,45 & 459,95 & 1170,05 \\
\hline Inlet system with a basic sieve & 351971,5 & 351326,2 & 154655,78 & 458,55 & 460,25 & 1170,35 \\
\hline Inlet system with a doubled sieve & 366122,2 & 340125,3 & 154192,9 & 460,65 & 461,95 & 1172,95 \\
\hline Inlet system with the finest sieve & 400157,2 & 327326,2 & 153674,3 & 470,01 & 471,15 & 1261,65 \\
\hline PARAMETER & $\mathbf{T}_{4 \mathrm{c}}$ & $\mathbf{Q}_{\mathrm{pal}}$ & $\mathbf{G}_{\text {pal }}$ & $\mathbf{c}_{\mathrm{h}}$ & $\mathbf{F}_{\mathbf{T}}$ & $\mathbf{c}_{\mathrm{m}}$ \\
\hline UNIT & $\mathbf{K}$ & $\mathrm{cm}^{3} /$ cycle & kg/cycle & kg.h ${ }^{-1}$ & $\mathbf{N}$ & kg.h $\mathbf{h}^{-1} \mathbf{N}^{1}$ \\
\hline Inlet system without a sieve & 1039,15 & 1407 & 1,09045 & 77,0065 & $732,5^{*}$ & 0,1051283 \\
\hline Inlet system with a fine sieve & 1041,15 & 1405 & 1,0889 & 78,8700 & $731,6^{*}$ & 0,107811 \\
\hline Inlet system with a basic sieve & 1043,45 & 1397 & 1,0819 & 75,2900 & $698,1 *$ & 0,107847 \\
\hline Inlet system with a doubled sieve & 1085,65 & 1330 & 1,0312 & 74,7434 & $598,74 *$ & 0,125334 \\
\hline Inlet system with the finest sieve & 1216,65 & 1293,3 & 1,0027 & 72,6600 & $541,11 *$ & 0,13428 \\
\hline
\end{tabular}

Table 2. Change in dependent MPM-20 parameters when throttling the inlet system.

\begin{tabular}{|c|c|c|c|c|c|c|c|c|c|}
\hline & $\boldsymbol{\pi}_{\mathbf{T}}$ & $\boldsymbol{\pi}_{\mathbf{K c}}$ & $\boldsymbol{\pi}_{\mathbf{V D}}$ & $\mathbf{T}_{\mathbf{2 c}}$ & $\mathbf{T}_{\mathbf{3 c}}$ & $\mathbf{T}_{\mathbf{4 C}}$ & $\mathbf{c}_{\mathbf{h}}$ & $\mathbf{F}_{\mathbf{T}}$ & $\mathbf{c}_{\mathbf{m}}$ \\
\hline $100 \%$ & 1 & 1 & 1 & $\mathrm{~K}$ & $\mathrm{~K}$ & $\mathrm{~K}$ & $\mathrm{~kg} \cdot \mathrm{h}^{-1}$ & $\mathrm{~N}$ & $\mathrm{~kg} \cdot \mathrm{h}^{-1} \cdot \mathrm{N}^{-1}$ \\
\hline $80 \%$ & 2,730 & 3,49 & 1,280 & 459,55 & 1169,25 & 1039,15 & 77,01 & 732,5 & 0,105128 \\
\hline $65 \%$ & 2,717 & 3,52 & 1,548 & 460,25 & 1170,35 & 1043,45 & 75,29 & 698,1 & 0,107847 \\
\hline $58 \%$ & 2,206 & 3,66 & 1,540 & 461,95 & 1172,95 & 1085,65 & 73,92 & 598,7 & 0,125334 \\
\hline $17 \%$ & 2,130 & 4,00 & 1,537 & 471,15 & 1261,65 & 1216,65 & 72,66 & 541,1 & 0,134280 \\
\hline
\end{tabular}

\section{Conclusion}

Following conclusions can be generalized from measured values of MPM-20 for individual experimental measurements:

1. The MPM-20 inlet device throttling leads to a change in engine parameters, whereas their character is the same like when changing the coefficient of total air pressure preservation in the inlet system $\sigma_{\mathrm{vst}}$.

2. The following thermodynamic parameters react the most intensively to the inlet device throttling: static gas pressure behind the gas turbine $\mathrm{p}_{4}(-19,39 \%)$, total gas temperature behind the gas turbine $\mathrm{T}_{4 \mathrm{c}}(-17,081 \%)$, total air pressure behind the compressor $\mathrm{p}_{2 \mathrm{c}}(-13,95 \%)$, total gas pressure in front of the gas turbine $\mathrm{T}_{3 \mathrm{c}}(-$ $7,903 \%)$, and total air temperature behind the compressor $\mathrm{T}_{2 \mathrm{c}}(-2,524 \%)$.

3. The MPM-20 inlet device throttling leads to intense approximation of the working point to the pumping border in the compressor characteristics. Despite higher resistance of the radial compressor MPM-20 against unstable work, $7^{\text {th }}$ measurement with $83 \%$ shadowing of the inlet device resulted in its stalls and destroyed blades of the gas turbine, and the sealing mass burnout in the gas turbine body above rotor blades. 


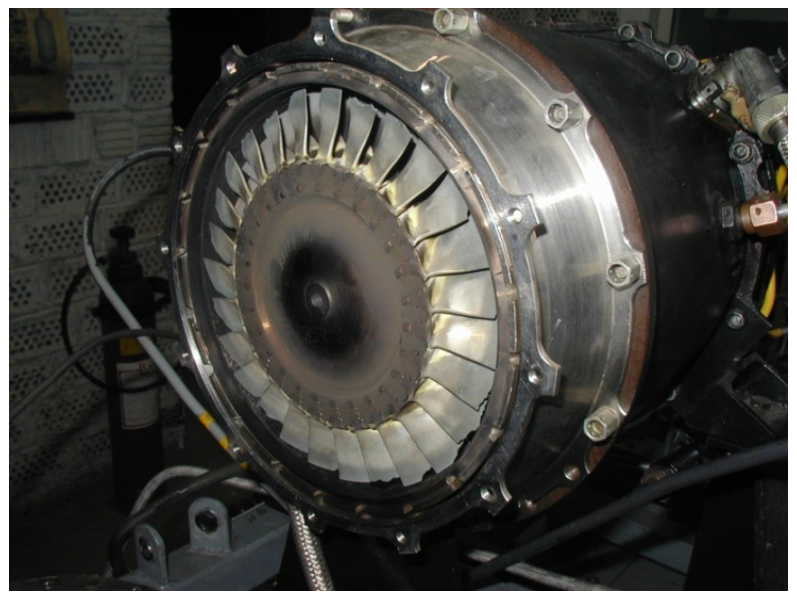

Figure 5. View at destroyed rotor blades of gas turbine MPM20

\section{Acknowledgement}

The presented research is supported by the project CZ.1.05/2.1.00/03.0108 (Sustainable Energy, SUSEN) and student project SGS-2014-070 (Increasing the efficiency, reliability and durability of power system devices 3 ).

\section{References}

1. L. T. De Luca, Propulsion physics (EDP Sciences, Les Ulis, 2009)

2. G. G. Ol'chovskij, Energetičeskije gazoturbinnyje ustanovki (Energoatomizdat, Moscow, 1985)

3. A. A. Inozemcev, V. L. Sandrackij, Gazoturbinnyje dvigateli (AOA Aviadvigatel', Perm, 2006)

4. A. J. Čerkez, Inžinemyje rasčoty gazoturbinnych dvigatelej metodom malych odklonenij (Mašinostrojenije, Moscow, 1965)

5. M. Hocko, M. Komjáty, Application of the method of small alterations to analyse funda-mental parameters of a small turbojet engine MPM-20 (Acta Avionica, 2014), ISSN 1335-9479

6. M. Hocko, Hodnotenie stavu LTKM na základe zmeny termodynamických parametrov (VLA M.R.Š., Košice, 2003)

7. T. Lazar, Inovatívne výstupy z transformovaného experimentálneho pracoviska s malým prúdovým motorom (Elfa, Košice, 2011) ISBN 978-80-8086$170-4$ 